\title{
Seniors, and their food handlers and caregivers, need food safety and nutrition education
}

\author{
by Mary L. Blackburn, Christine M. Bruhn, Lisa \\ Soederberg Miller, Chutima Ganthavorn and \\ Beth Ober
}

Seniors are at greater risk than other adults for foodborne illness, poor nutrition and high rates of nutrition- and lifestyle-related chronic diseases. They also represent $a$ major underserved segment of the UC Cooperative Extension client population. The Make Food Safe for Seniors (MFSFS) initiative assessed food safety and nutrition education needs of fixed-income seniors and food handlers and caregivers serving seniors in 10 California counties. Baseline survey results found unsafe practices by over $50 \%$ of the participants in six areas and by over $65 \%$ of participants in three of those areas. After one food safety training, a post-test showed an average knowledge gain of $18.1 \%$; seniors had gained the least knowledge, food handlers had gained some knowledge, and caregivers had gained the most. The unsafe food handling practices of a majority of the study group, as well as poor food behaviors, suggested areas in which education could reinforce or improve food safety, healthy eating and disease prevention practices of seniors, caregivers and food handlers serving seniors.

\footnotetext{
$\neg$ he coming of age of baby boomers accelerated the rate at which California's population is turning gray. In "The Graying of California," a special issue of this journal, UC Division of Agriculture and Natural Resources (UC ANR 2010) acknowledged this as an emerging concern. Public health professionals for many years have been concerned that the workforce is not adequately prepared for the needs of America's aging population (Krisberg 2005). In our research we were concerned about the rapidly increasing numbers of older Californians at greater risk for foodborne illness (food poisoning) as well as
}

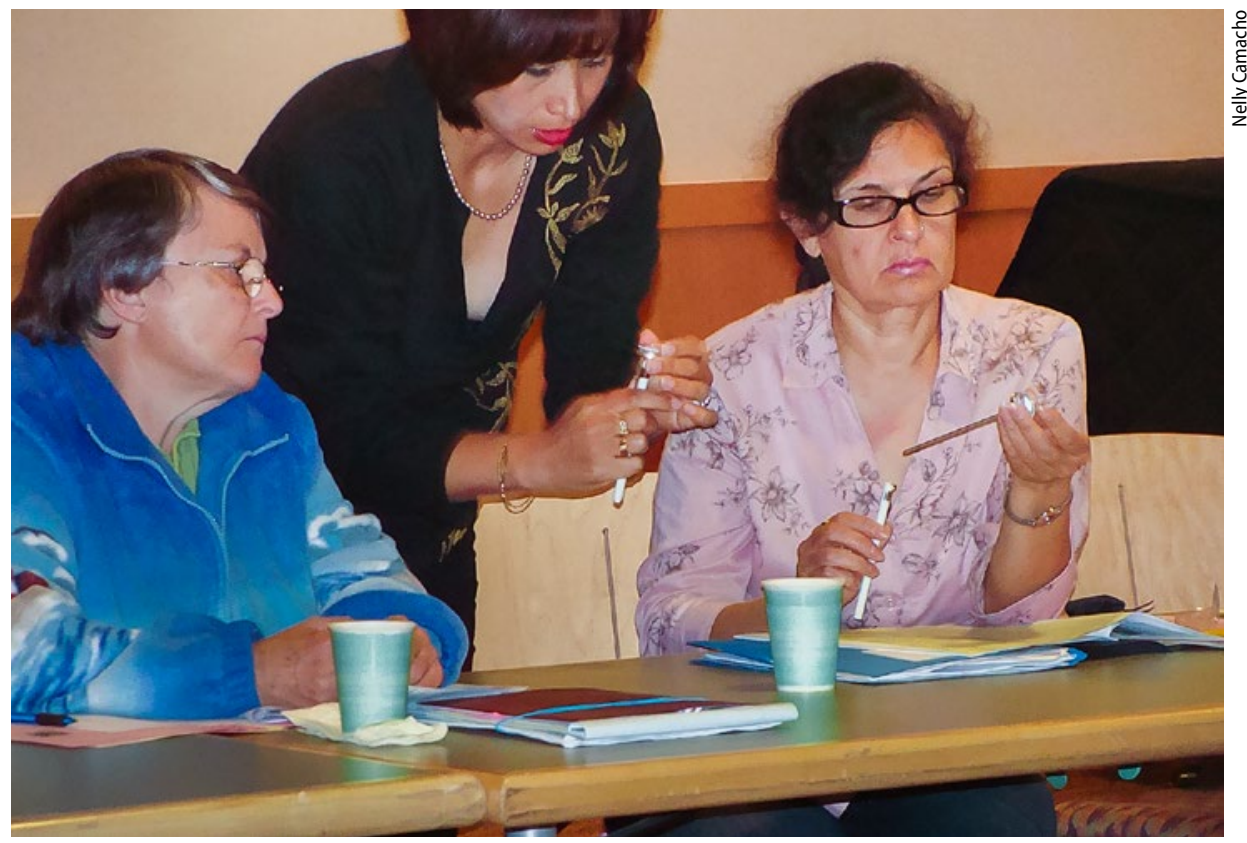

In a study of the food safety and nutrition practices of senior citizens and their food handlers and caregivers, UC Cooperative Extension researchers identified a need for food safety and nutrition curricula aimed at seniors and those who prepare their food. Above, participants at a food safety training in Alameda County learn how to calibrate a food thermometer.

their need for nutrition education to promote healthy aging (Blackburn 2010).

\section{Risk of foodborne illness}

Adults over the age of 60 are more likely than younger adults to experience complications, hospitalization and death because of foodborne infections (Cates et al. 2009). Seniors with diminished capacity or physical impairment - who are taking multiple medicines or have weakened immune systems - are less able to fight foodborne pathogens, such as Salmonella, Escherichia coli O157:H7 and Listeria, and other bacterial or viral infections (Kendall et al. 2006).

About $80 \%$ of seniors in the United States have at least one chronic health condition, and $50 \%$ have at least two; some chronic conditions render them more susceptible to foodborne illness (CDC 2011a). About 3.6 million Californians are over age 65 . At least $55 \%$ of these seniors suffer from hypertension, 50\% from arthritis, $24.0 \%$ from heart disease, $17.3 \%$ are diagnosed with cancer and $14.8 \%$ have diabetes. These top five chronic disease conditions vary significantly in California by ethnic group (Wallace et al. 2003) (fig. 1).
Of major concern are those seniors who are suffering from deficits in memory functioning. Lapses in episodic memory (the recollection of personally experienced events) are an important contributing factor to unsafe food handling, missed or mistakenly repeated doses of medications and other high-risk behaviors (Ober 2010). This memory impairment is the hallmark of Alzheimer's disease, which occurs in $14.7 \%$ of 85 -year-olds and $4.2 \%$ of 75 -year-olds (Brookmeyer et al. 2007).

Safe food handling knowledge and skills are critical for seniors so they can recognize unsafe practices that may be used by untrained food handlers in community-based organizations or by untrained agency or kinship caregivers who lack knowledge of safe food handling. Many who provide food to seniors in need of assistance may not be aware that elderly populations are more vulnerable to foodborne illness. The population of seniors receiving care is significant:

Online: http://californiaagriculture.ucanr.edu/ landingpage.cfm?article=ca.v068n01p30\&fulltext=yes doi: 10.3733/ca.v068n01p30 
California's In-home Supportive Services's case load in June 2012 was 432,650 people (CAPA IHSS 2012).

Low availability of food, insufficient resources and hunger may also contribute to the risks of foodborne illness among seniors. Hoarding food is a natural response in times of limited food supply, and unsafe food items may not be discarded. Concerns about finances among limitedand fixed-income elders in the current economic environment may be escalating: poverty estimates indicate that 810,000 of 4.3 million older Californians live in poverty (Bohn et al. 2013), and many fixedincome seniors live on an income that is $50 \%$ or less of the benchmark income for poverty in the United States.

\section{Causes of foodborne illness}

Primary factors contributing to foodborne illness are improper temperature, inadequate cooking, contaminated utensils or equipment, eating food from unsafe sources and poor personal hygiene. Research shows that elders who take food home from group sites or have homedelivered meals may fail to properly store or reheat the food. A study of the average wait time between when prepared meals are home delivered and when they are consumed found $63 \%$ of seniors ate their meals when delivered, $29 \%$ stored them in the refrigerator or freezer and $8 \%$ left

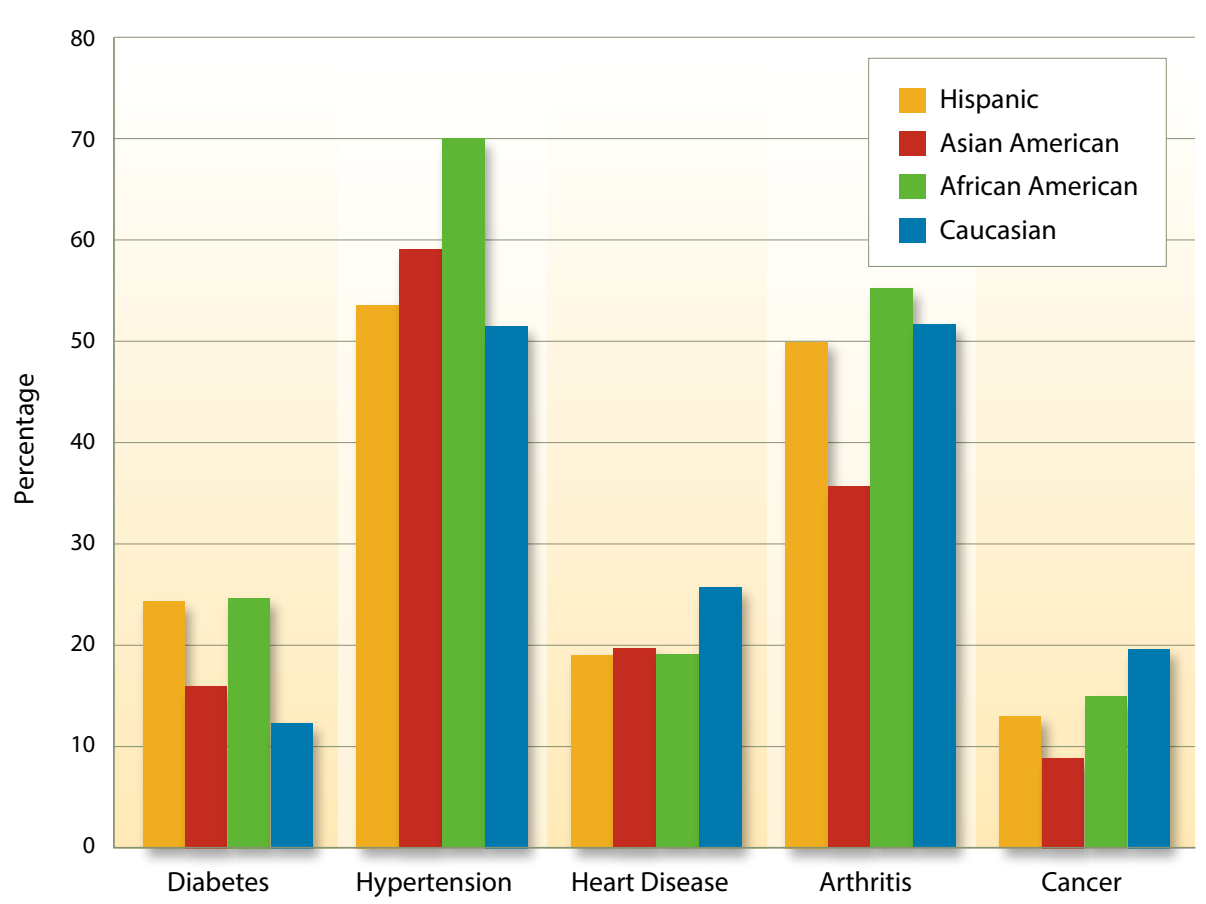

Fig. 1. Top five chronic diseases in California by ethnic group. Source: Wallace et al. 2003.

\section{Foodborne illness in California}

In 2011, the Centers for Disease Control (CDC) estimated that annually one in six Americans, or 48 million people, experience a foodborne illness; 128,000 are hospitalized, and 3,000 die (CDC 2011b). An earlier report combining data from multiple surveillance systems and sources estimated foodborne diseases cause approximately 76 million illnesses, 325,000 hospitalizations and 5,000 deaths in the United States annually (Mead et al. 1999). A recent study using the CDC model to determine cost, and adding consideration for pain suffering and functional disability, estimates an annual cost for foodborne illness of $\$ 77.7$ billion (Scharff 2012). Increased rates of food-borne illness are associated with eating more food away from home, emerging food-borne pathogens, and a growing aging population more susceptible to foodborne illness.

The Centers for Disease Control Food Net Report (CDC 2011c) found a significantly higher incidence of at least five pathogens (Campylobacter, Listeria, Salmonella, Shigella and Vibrio) in California compared to a 10-state average. Cases of Campylobacter in California were 32.50 per 100,000 compared to the 10-state average of 13.52 cases (CDC 2011c). A 10-year review of California outbreaks from 1998 to 2007 found restaurants and other food establishments to be the most common locations for outbreaks (44\%), followed by private homes (21\%), multiple locations or unknown (8\%) and the workplace (7\%) (CSPI 2011). California Department of Health Services reported about $26 \%$ of foodborne illness is associated with food prepared in community locations such as potlucks or church dinners, $46 \%$ with restaurants, 19\% with in-home preparation and 6\% in schools (Wang 2000). them out. About $35 \%$ reported leftovers, but only $12 \%$ ate the leftovers within 2 hours as recommended (Almanza et al. 2007).

Another assessment of home-delivered meals $(n=179)$ found $58 \%$ of mostly older (age 80 and above) seniors stored all or some of the food. Of the older seniors who saved their food, $38 \%$ stored it in the refrigerator, but $30 \%$ stored it on the counter (Fey-Yensan et al. 2001). A study of 120 senior meal recipients, mostly females over age 70 , found about $64 \%$ knew the importance of hand-washing but were not aware of when and how to wash hands (Lee et al. 2009). Lee and colleagues also found that home-delivered meal recipients $(n=97)$ had an average score of $63.8 \%$ in food handling, but $49 \%$ for cleaning, sanitizing and washing dishcloths.

A national representative Web-based survey $(n=2,060)$ examined refrigerator temperatures, use of thermometers and frequency of cleaning home refrigerators. About one half of all participants in the study had cleaned their refrigerator in the last month, but only $11 \%$ had a thermometer in their refrigerator (Kosa et al. 2007). More of the older adults (77.5\%) were likely to have their refrigerator at the right temperature than the younger population $(70.4 \%)$. However, older adults who were unmarried or lived alone were less likely to have a thermometer or have their refrigerator at the recommended temperature $\left(40^{\circ} \mathrm{F}\right.$ or below). More recent research shows an increasing trend in consumer food thermometer ownership from $49 \%$ in 1998 to $70 \%$ in 2010 . The study found the elderly, 65 to 101 years old, were less likely to use a food thermometer for roasts and chicken parts than adults 18 to 29 years old (Lando and Chen 2012). 


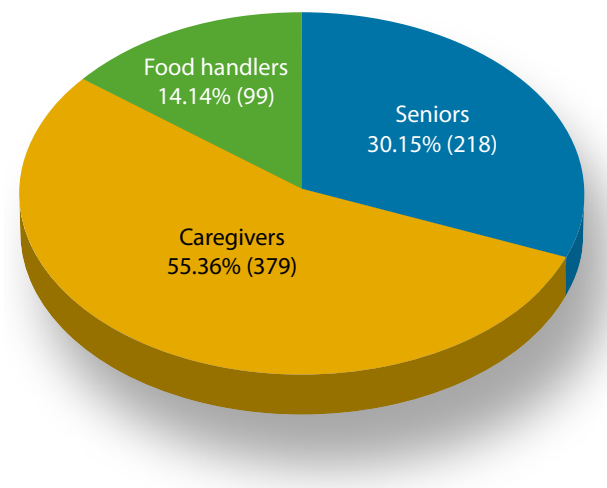

Fig. 2. Study group was composed of 696 participants, including seniors who volunteered from senior centers and senior programs, caregivers from in-home supportive services and family or relative caregivers, and food handlers from church communities and food pantries.

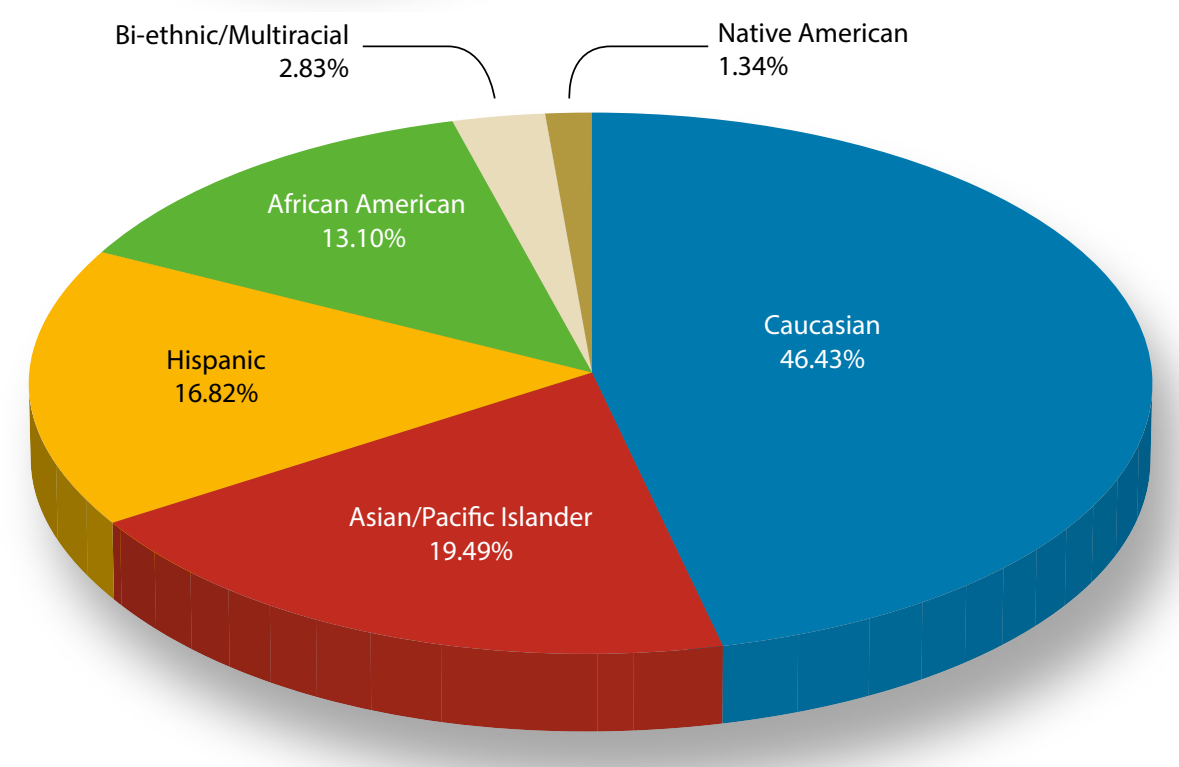

Fig. 3. Study participants by ethnic distribution. Total number of participants who provided ethnic information was 672 .

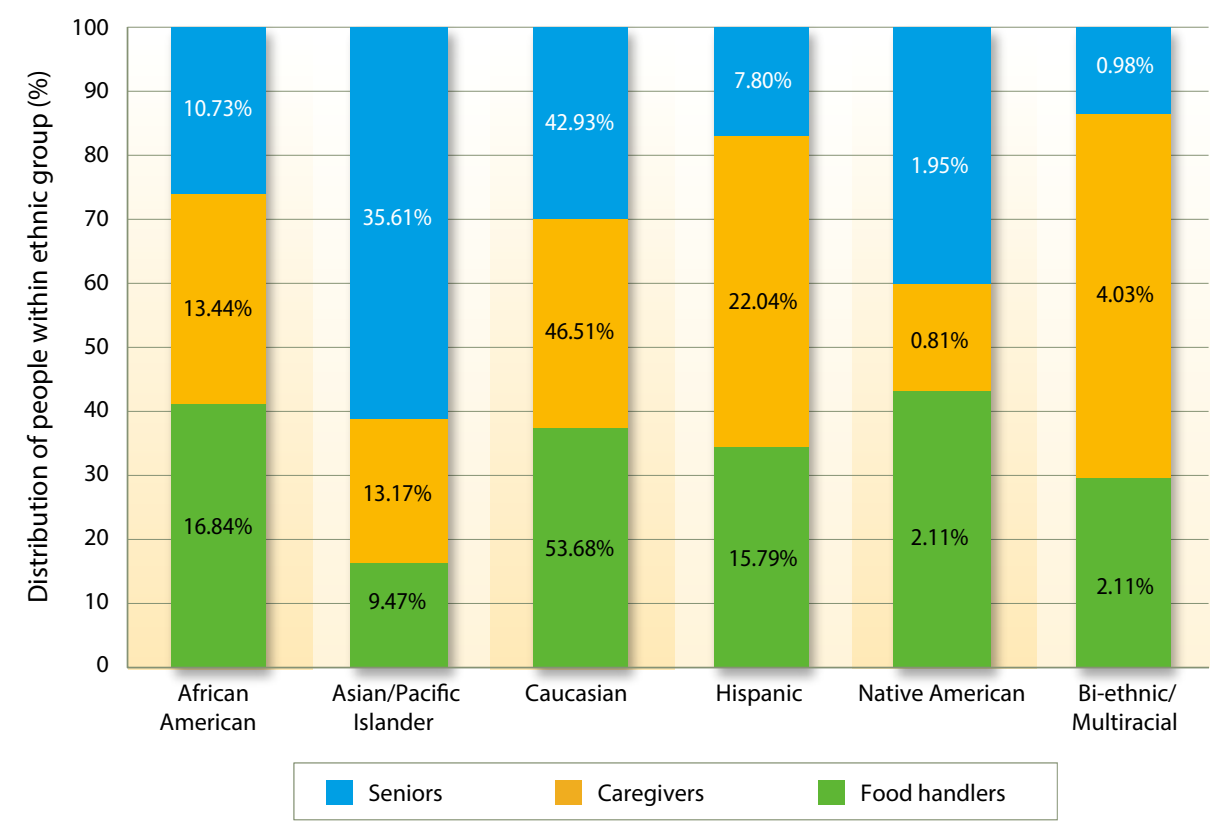

Fig. 4. Ethnicity of the seniors, caregivers and food handlers (read each color across the figure); and within each ethnic group, the percentage who were seniors, caregivers and food handlers (read the size of each color unit against the vertical axis).

\section{Make Food Safe for Seniors (MFSFS)}

The Make Food Safe for Seniors (MFSFS) initiative is a joint research venture, funded by a CORE issues grant, between two UC ANR workgroups Aging Californians in Rural and Urban Settings, and Food Safety. The research team was comprised of two Agriculture Extension Station scientists focusing on aging; a Cooperative Extension food safety specialist; nine Nutrition, Family and Consumer Sciences (NFCS) advisors; and county directors and community collaborators in 10 counties.

The objectives of the MFSFS initiative were to a) determine the baseline nutrition education and food safety needs of limited- or fixed-income seniors, food handlers in senior services and in-home caregivers, b) increase the food safety knowledge and skills of the study group, c) increase public awareness of the higher risk of foodborne illness among elders, $d$ ) use the findings to create senior-friendly curricula and materials to help reduce the risk of foodborne illness and e) promote healthy food practices for vulnerable elders in local California counties.

Local needs assessments. The MFSFS team reviewed existing research and assessments of nutrition and food safety needs in local counties. Research by Barrett et al. (2005) with in-home caregiver trainees $(n=482)$ in Sacramento and Yolo Counties documented a dire need for standardized nutrition education and safe food handling curricula for caregivers working with frail elders aging in place. The 2009 California Health Interview Survey health risk data for baby boomers (both informal caregivers $[n=5,688]$ and noncaregivers $[n=12,941]$ ) show that those who are also caregivers have greater odds of overall negative health behaviors associated with disability and chronic illnesses (Hoffman et al. 2012).

Blackburn (2010) assessed the nutrition and wellness needs of limited-income seniors at 20 sites $(n=377)$ in Alameda County. About $40 \%$ of the seniors reported multiple chronic diseases, and approximately $88 \%$ expressed a need for more healthy nutrition, lifestyle and food safety information, for example on cooking, preventing spoilage, and storing food over extended periods.

A 2005 Aging Californians workgroup survey of 27 NFCS advisors and county directors found few counties offered 
senior programs, but $86 \%$ said aging programs were needed in their counties (2005 Aging Workgroup, unpublished data).

Process. Our research protocol and evaluation tools were approved by UC Davis Office of Research Institution Review Board. An existing UC-approved food safety curriculum was adapted to reflect the needs and circumstances of the elderly and to effectively teach knowledge and skills to seniors, food handlers in senior programs and in-home caregivers. Cooperative Extension educators assessed and trained 696 participants from 10 counties ( 379 caregivers, 218 seniors and 99 food handlers) (fig. 2). Participants were from senior centers, senior food programs, in-home supportive services, and kinship caregivers. Ethnic composition of the study group was diverse (fig. 3), and the representation of seniors, food handlers and caregivers within each ethnic group is shown in figure 4 .

Data collection. Baseline data were collected between January 2008 and March 2009 with an 11-question pre-test of food safety knowledge and practices; the same questions were asked in the post-test later. Participants $(n=696)$ received 2 to 3 hours of interactive education in groups ranging in size from 10 to 22 participants. The education included information on the incidence of foodborne illness, which groups are at greater risk, causes and sources of foodborne illness, as well as the four basic components of food safety: cleanliness (personal hygiene, hand-washing and washing foods); proper cooking and chilling temperatures; keeping food at the right temperature and use of thermometers; and storing food to prevent cross contamination of raw and cooked meat or contamination by chemicals or objects.

Baseline food behavior data also were collected before the food safety education with a USDA-approved food behavior checklist that was filled out by 506 of the 696 study participants. The checklist contains 21 questions about meal planning, food buying, food safety practices, healthy food choices, food preparation practices, reducing salt and fat intakes, eating fruits, vegetables and whole wheat bread, food availability and food security, eating out, and eating breakfast.

Data analysis. The change in food safety knowledge as a result of the training was derived by comparing the pre-test and post-test scores of correct responses

\section{The Nutriture of People}

From The Yearbook of Agriculture (USDA 1959), "The Nutriture of People"

1959 "... Although more Americans over 60 own their own homes than do younger people, institutions for older persons also are increasing more rapidly than for any other age group.

"Institutional food service generally is planned to provide approximately the amounts of nutrients recommended for the largest group in the institution. Several studies between 1948 and 1956 of older groups in insti-

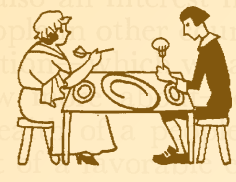
tutions have indicated however, that the daily meals, as served, may provide recommended amounts of nutrients, but the actual nutrient intake levels of the older individuals often are below the recommended amounts.

"This situation is not unlike comparisons of intake levels of families as a whole and of the individual members of families. Among the groups in large institutions, however, there is less consideration of individual food habits and food preferences in planning menus than there would be for family groups.

"Studies by the California, Florida, and Rhode Island Agricultural Experiment Stations between 1950 and 1956 indicated that the nutrient intake levels of older groups in institutions generally are substantially lower than the nutrient intake levels of older persons in individual homes. Most of the residents in public institutions consumed considerably less than recommended amounts of all nutrients....

"When their intakes of iron and of protein were adequate, some relationship was evident between the intake of iron and protein and the hemoglobin. When

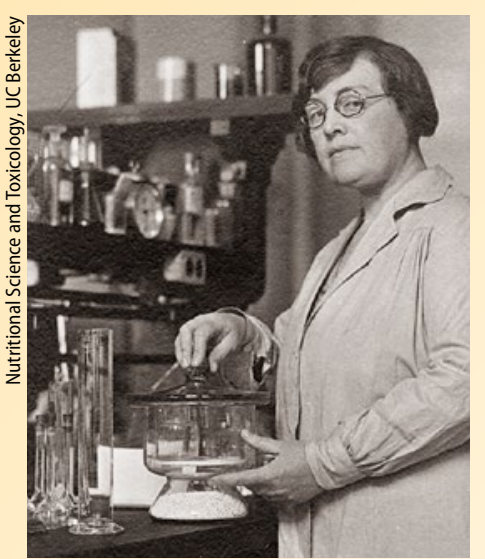

UC Professor Agnes Fay Morgan. intakes of iron and protein are generally high, hemoglobin levels may be rather consistent - an indication that hemoglobin beyond certain intake levels does not generally increase with higher intakes."

Agnes Fay Morgan, co-author of the essay excerpted above, was a pioneer among women in American science. Morgan came to UC Berkeley's faculty in 1915. The next year, she became a founding co-chair of the Department of Home Economics. Two years later she was sole chair of the new Department of Household Science, within UC Berkeley's College of Agriculture. Her goal was to validate or debunk common household customs of cookery, clean living and good order by scientific means, and in that way promote sound practices in this tradition-bound arena. Those who studied under Morgan were well qualified to teach science and nutrition courses, along with the cooking and sewing classes one might expect of a home economics graduate.

Morgan's service to the University has been recognized in many ways, including a special symposium held on the 50th anniversary of her joining the faculty and the naming of Agnes Fay Morgan Hall, UC Berkeley's nutrition building, in herhonor.

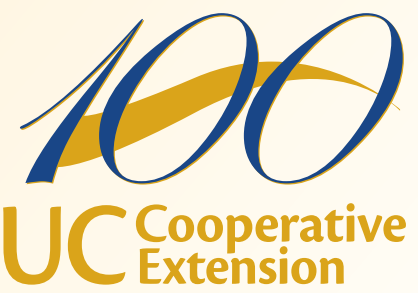

A Celebration of Science and Service 
for individuals and the overall group. The $P$ value for knowledge gain was derived by determining the probabilities of getting all answers correct for all the choices in the 11-question test. The pre-test null hypothesis - that is, the array of pre-test probabilities for correct answers - was determined by this formula:

If $n=$ number of choices and $c=$ number correct, then

$$
\mathrm{P}(c)=c !(n-c) ! / n ! \times 100 \%
$$

To construct a null hypothesis for the post-test, one must account for the effects of the training intervention. In this study, it meant reducing the number of choices by counting each correct answer as " 1 ", which was selected because a larger integer eliminates choice for questions with just 2 possible correct answers. When choices are reduced by 1 , the null hypothesis for each question (probability of correct answers by chance) increased by a certain percentage.

Baseline food behavior practices, from the food behavior checklist assessment, were entered into an Excel database, summarized, normalized and examined to

TABLE 1. Correct pre- and post-test responses to food safety questions*

\section{Question}

Pre-test Post-test

1. Groups at highest risk for foodborne illness:

young children

61

older adults

people with diabetes

people with chronic disease

people with weakened immune systems

pregnant women

grandfathers over 50 years of age

2. Foodborne illness is not always caused by something eaten in the last 12 to 14 hours.

3. Bacteria and viruses are the most common causes of foodborne illness.

4. Potential sources of harmful bacteria include

homegrown produce

organic produce

commercial produce

raw meat or poultry

unwashed hands

insects

5. Appearance, odor, and taste cannot determine if food is safe to eat.

6. Washing hands with warm water and soap is recommended.

Washing raw meat and poultry with running water is not recommended.

Washing fruits and vegetables with running water is recommended.

Washing and sanitizing sink before and after food preparation is recommended to prevent cross contamination.

7. Using separate cutting boards for raw meat and fresh produce is recommended. Discarding old cutting boards with many cuts and grooves is recommended.

Plates/platters/pans used to hold raw meat should be rinsed with running water before used to hold cooked meat (incorrect as written: rinsing is not sufficient to destroy bacteria).

Storing raw foods below cooked foods in the refrigerator is recommended.

8. Using a thermometer is the most accurate way to tell if meat/poultry is cooked safely.

9. Chilling foods within 1 hour if warmer than $90^{\circ} \mathrm{F}$ is recommended. Chilling foods within 2 hours if cooler than $90^{\circ} \mathrm{F}$ is recommended.

10. Storing foods in shallow containers in the refrigerator is recommended.

11. Refrigerator temperature should be $40^{\circ} \mathrm{F}$ or below.

* Study participants ( $n=696$ ) were comprised of 379 caregivers, 218 seniors and 99 food handlers. determine the baseline nutrition education needs of the participants. Results from different questions were grouped into acceptable behavior targets toward achieving larger nutrition goals such as reducing fat, salt and sugar in the diet.

\section{Baseline/pre-test results}

Baseline food safety test results, before the training, show a serious need for basic food safety knowledge to help prevent foodborne illness among at-risk seniors. Many participants lacked correct information about cooking and cooling temperatures. For example, only $57 \%$ believed using a thermometer was the most accurate way to determine if foods are adequately cooked.

Pre-test data show more than $50 \%$ of the study group participants answered incorrectly six of the 11 food safety questions: $66 \%$ provided an incorrect response to the statement that "foodborne illness is not always caused by something eaten in the last 12 to 14 hours"; $64 \%$ believed, incorrectly, that appearance, odor and taste can determine if food is safe to eat; $65 \%$ did not know that food should be stored in shallow containers; $73 \%$ reported incorrect answers about chilling food when the temperature is less than $90^{\circ} \mathrm{F}$ and $34 \%$ when the temperature is over $90^{\circ} \mathrm{F} ; 43 \%$ did not know that using a thermometer is the most accurate way to determine if food is accurately cooked; and $51 \%$ incorrectly identified the recommended refrigerator temperature. Also, many participants did not recognize the population groups at increased risk for foodborne illness: 70\% identified older people as a group at risk but only $40 \%$ identified grandfathers; $40 \%$ knew that pregnant women are at risk; $45 \%$ identified diabetics as at risk; $46 \%$ knew people with chronic diseases are at risk; and $62 \%$ recognized people with weakened immune systems as being a vulnerable group for foodborne illness (table 1).

\section{Knowledge gain/post-test results}

To assess the rate of knowledge gained from pre-test to post-test, a null hypothesis was derived that represented the difference between post-test and pre-test probabilities for correct answers. We used a chi-squared test to compare the actual knowledge gain to the expected (null hypothesis) knowledge gain. The comparison produced a probability $(P$ 
value) that was at least as extreme as the null hypothesis (cut-off 0.05). Evaluation of the total group $(n=696)$ found an average increase in the percentage of correct responses from $58.0 \%$ to $76.1 \%$, a knowledge gain of $18.1 \%(P=0.4930)$. The gains of seniors $(10.4 \%, P=0.0404)$ were much lower than those of the in-home caregivers $(23.4 \%, P=0.9045)$ and food handlers $(18.1 \%, P=0.7195)$ as shown in figure 5 . By ethnicity, $P$ values for knowledge gain were Native American $P=0.9966$, Hispanic $P=0.9960$, Caucasian $P=0.7681$, Bi-ethnic/Multiracial $P=0.6846$, African American $P=0.6060$, and Asian/Pacific Islander $P=0.0031$ (fig. 6). The size of the Native American and Bi-ethnic/ Multiracial groups were comparatively small, 9 and 19 participants, respectively, but all ethnic groups had significant gains in knowledge at different rates except for Asian/Pacific Islander $(P=0.0031)$.

\section{Baseline food/nutrition behaviors}

Table 2 summarizes the baseline food behaviors of the 506 study participants who completed the food behavior checklist. Of significance are the questions about food insecurity - $46 \%$ often worried about running out of food, $10 \%$ reported that they actually ran out and 31\% felt it was too expensive to eat a lot of nutritious food. The research team grouped a series of baseline healthy behaviors into target goals under the areas listed in table 2. The performance of the group in relation to these goals was determined by Boolean analyses to detect deterministic dependencies between observed response patterns. Baseline performances of the study group to meal planning and shopping target goals are displayed in figure 7 .

\section{Training needs, considerations}

In the food safety knowledge pre-test, the MFSFS research team found food safety practices similar to the findings of a national representative survey $(n=$ 1,140 ); older adults think they are knowledgeable about food safety but do not follow recommended food safety practices (Cates et al. 2009). Dutram et al. (2002) reported food safety education improved safe food-handling practices among lowincome elders participating in congregate meal programs and home-delivered meal programs. The MFSFS post-test results point to a similar conclusion. The national study of older people by Cates et al. (2009) suggested men in particular and individuals with high income or education levels also need food safety education.

The positive findings in the MFSFS study were that in the pre-test $66 \%$ knew cooked food should be refrigerated within 1 hour if the temperature is over $90^{\circ} \mathrm{F}$, and $67 \%$ knew the correct refrigerator temperature at post-test. Of most concern was the lack of knowledge about cross contamination of raw and cooked meat, potential

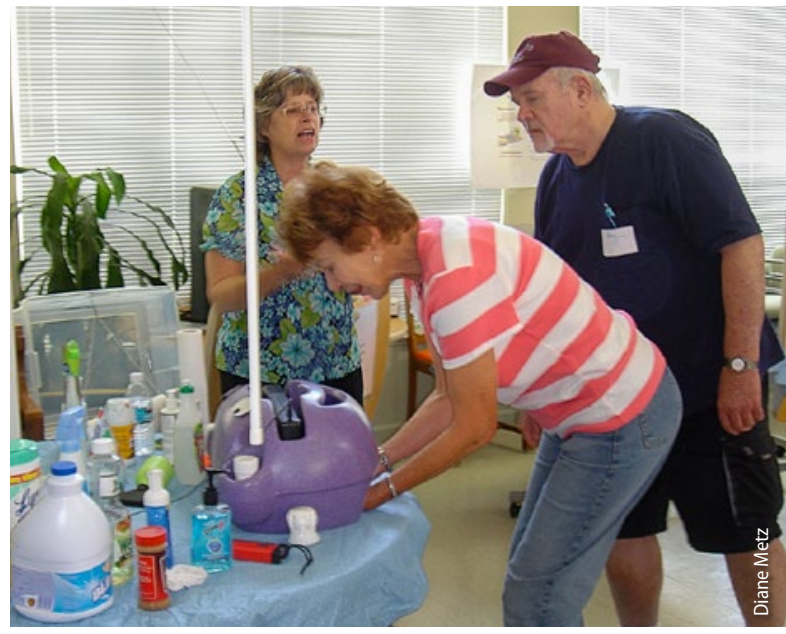

At a food safety training in Davis, Calif., participants used a GlitterBug UVA lamp to find out how thoroughly they washed their hands.

sources of harmful bacteria, proper use of a thermometer to accurately determine if food is adequately cooked (some used taste, smell and appearance to determine if food is safe) and the increased risk with age for foodborne illness. By groupings, seniors knew relatively less than the food handlers or caregivers.

The research study was limited to a convenient sample of 696 people.

Therefore, the results are not derived from a population-based sample, but they may point to the need for food safety as well as nutrition education among participants in UC Cooperative Extension's Nutrition, Family and Consumer Sciences programs.

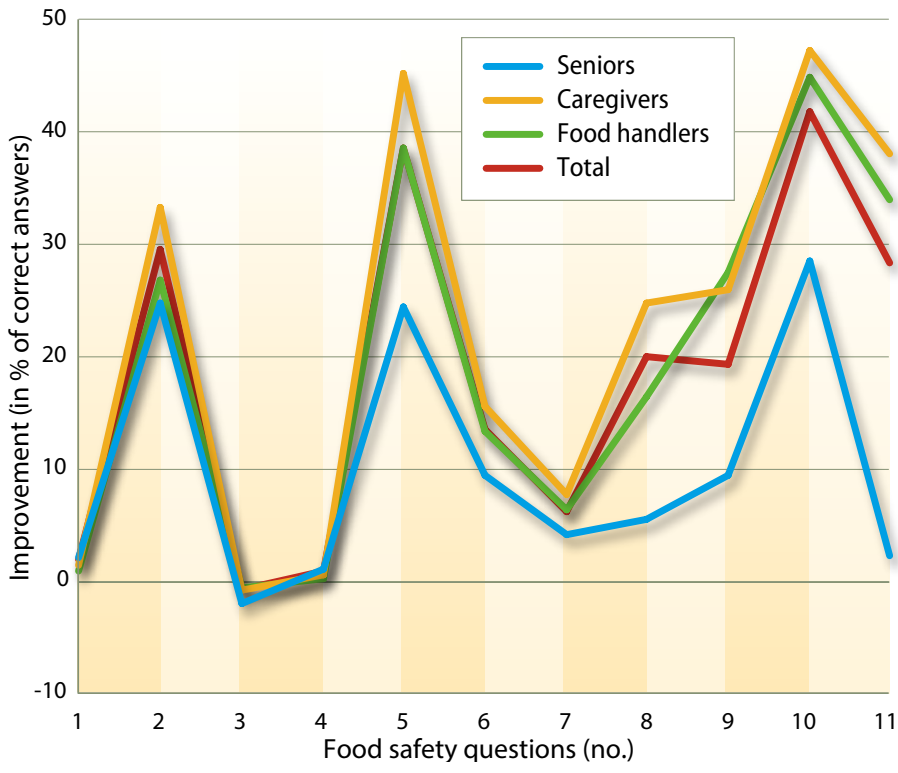

Fig. 5. Knowledge gained from pre-test to post-test. Study group was comprised of 218 seniors, 379 caregivers and 99 food handlers (from church communities and food pantries). A chi-squared test was used to compare the actual knowledge gain to the expected knowledge gain.

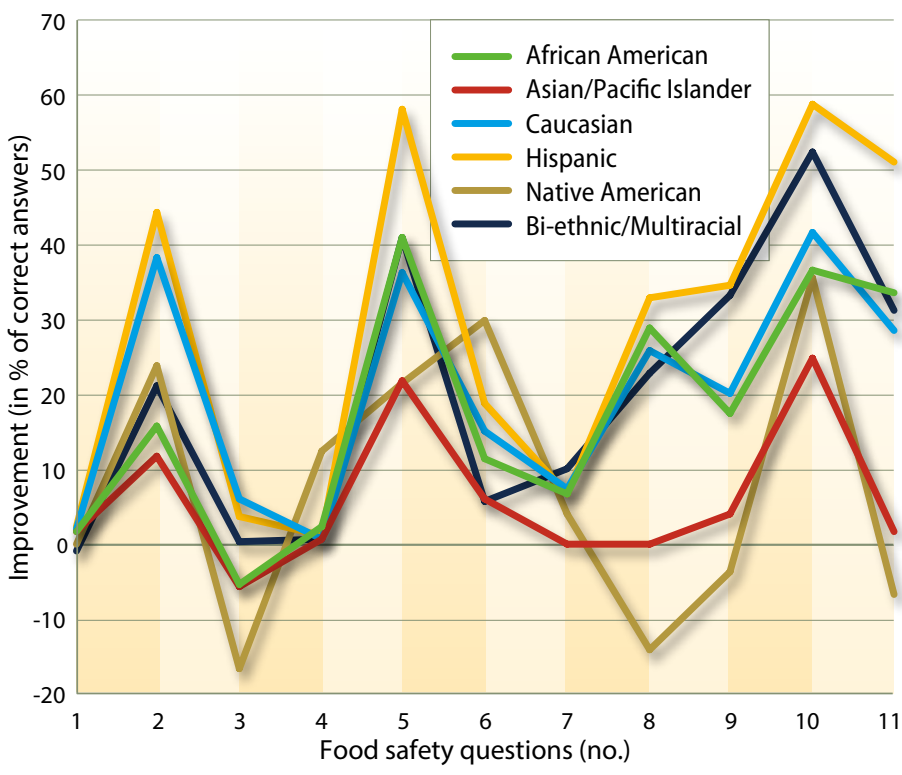

Fig. 6. Knowledge gained from pre-test to post-test by ethnicity. 
TABLE 2. Baseline food behaviors of participants, before training

\begin{tabular}{|c|c|c|}
\hline Food behavior areas & Specific behaviors & $\begin{array}{l}\text { Percentage of } \\
\text { participants }\end{array}$ \\
\hline \multirow[t]{3}{*}{ Meal planning and shopping } & Planned meals ahead & $47 \%$ \\
\hline & Prepared a shopping list & $62 \%$ \\
\hline & Compared prices & $73 \%$ \\
\hline \multirow[t]{6}{*}{ Considerations of healthy food } & $\begin{array}{l}\text { Thought about healthy foods when they made } \\
\text { food selections }\end{array}$ & $83 \%$ \\
\hline & Read food labels & $57 \%$ \\
\hline & Chose foods low in salt or cooked with less salt & $46 \%$ \\
\hline & Usually ate foods low in fat & $62 \%$ \\
\hline & Chose low-fat milk & $62 \%$ \\
\hline & Removed fat from chicken & $65 \%$ \\
\hline \multirow{3}{*}{$\begin{array}{l}\text { Fruit, vegetables and whole } \\
\text { grain practices }\end{array}$} & Usually ate more than one kind of fruit each day & $57 \%$ \\
\hline & Ate more than one kind of vegetable each day & $62 \%$ \\
\hline & Usually selected whole wheat bread & $73 \%$ \\
\hline \multirow[t]{3}{*}{ Food insecurity } & Ran out of food before the end of the month & $10 \%$ \\
\hline & $\begin{array}{l}\text { Often or usually worried about running out of } \\
\text { food before they could buy more food }\end{array}$ & $46 \%$ \\
\hline & $\begin{array}{l}\text { Strongly agreed or agreed that it was too } \\
\text { expensive to eat a lot of nutritious foods }\end{array}$ & $31 \%$ \\
\hline Food safety & $\begin{array}{l}\text { Did not leave meats and dairy out of the } \\
\text { refrigerator more than } 2 \text { hours }\end{array}$ & $69 \%$ \\
\hline Eating out & Ate in restaurants an average of & 1.59 times/week \\
\hline Soda consumption & Usually or often drank regular sodas each day & $19 \%$ \\
\hline
\end{tabular}

$n=506:$ All participants combined.
Key to the effectiveness of food safety education among elders is the method of information delivery. Kosa et al. (2011), in a randomized control evaluation of the effectiveness of Web-based and print materials with older adults, found no significant differences between the two delivery methods. They suggested focusing education on a limited number of practices and combining print materials with personal contacts.

The MFSFS training used a clientcentered, senior-friendly, interactive and hands-on educational approach, which achieved an average knowledge gain of $18.1 \%$. Interactive education has been used very successfully in the Alameda County Quality of Life education program since 1993, and most recently in the 2012 Staying Healthy nutrition education program, completed by over 260 seniorhousing residents with a graduation rate higher than $95 \%$.

The research findings suggested the levels of knowledge retention differed among the three groups (seniors, food handlers, caregivers). The caregivers (some were much younger than the seniors) as well as the food handlers may have had some or more exposure to food

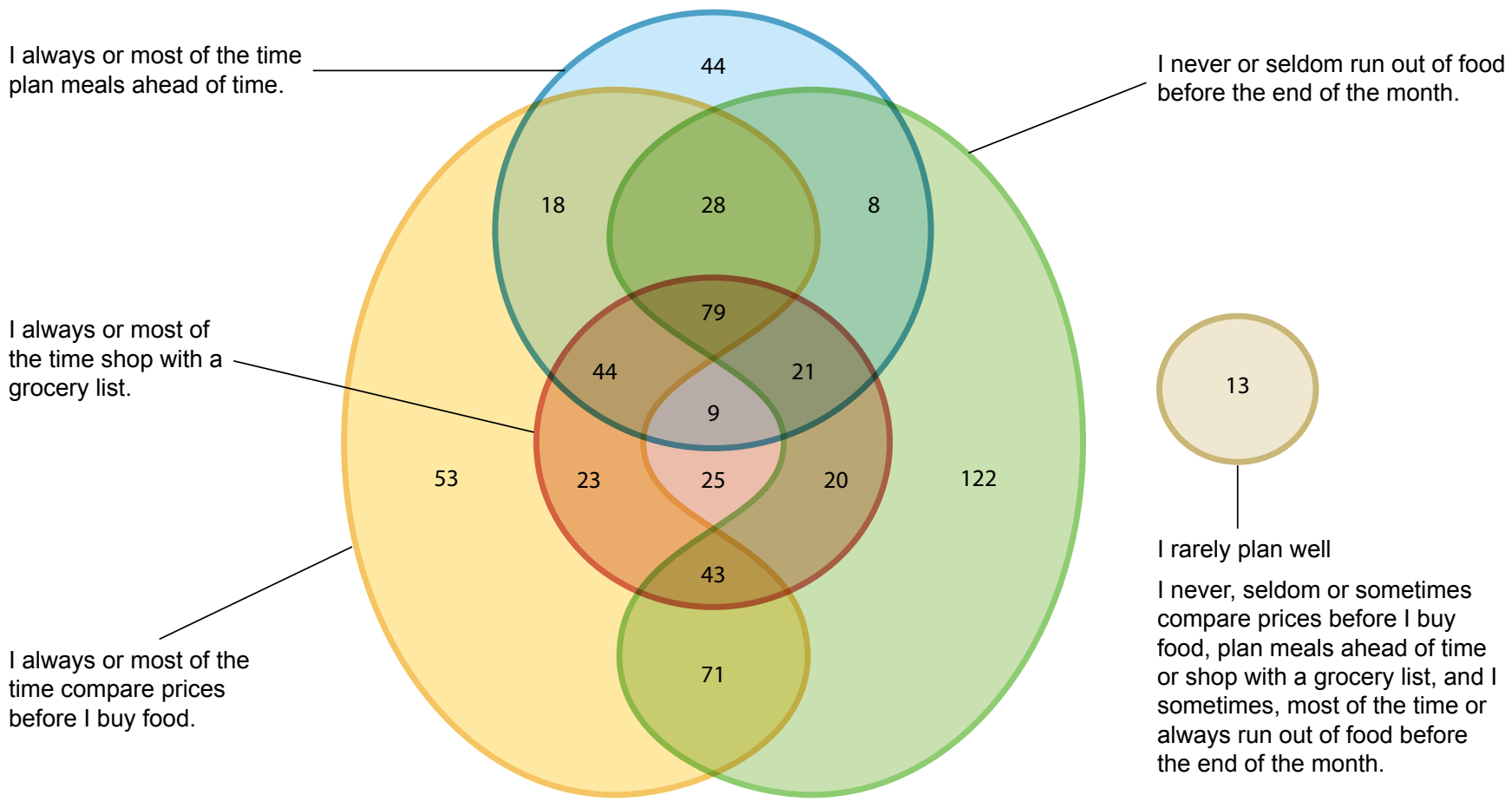

Fig. 7. Learning targets for good meal planning and shopping behavior goals, and the number of participants in the study group ( $n=621)$ achieving them: $2.09 \%$ of the participants achieved no target (rarely plan well); $39.29 \%$ achieved one; $23.99 \%$ two; $21.90 \%$ three; and $12.72 \%$ all four targets. 
safety information than the seniors. Research shows that older adults with prior knowledge of health information can retain it at levels that resemble those of young adults (Miller et al. 2013). Other research shows that with age, certain normal changes occur with the loss of episodic memory that might impact comprehension and knowledge retention (Ober 2010).

For older adults with low knowledge and those with low literacy, training must be tailored to fit individual learning needs (Miller 2010).

\section{Potential for new curriculum}

A 2008 statewide meeting of the ANR Umbrella Nutrition Workgroup voted a caregiver curriculum and training program to be a priority, and the 2010 special issue in California Agriculture on aging stated the need to assess the unique nutrition and wellness needs of aging Californians (Blackburn et al. 2010). Our research supports the need for training older adults and those who prepare their food to address food safety needs in the home and community. The training must seek to increase a) declarative and procedural knowledge surrounding food safety standards and b) skills surrounding how to apply those standards to ensure safe food preparation and storage. Importantly, the training also must be tailored to those most at risk for foodborne illness.

The data collected by the research team, described here, provides a knowledge base that could be used for Cooperative Extension nutrition and food safety curricula for seniors and caregivers in California and also to heighten awareness of the food safety needs of California's elders. The researchers have distributed this information through UC Delivers, a UC ANR website (http://ucanr. edu/delivers/), and through conference presentations, peer-reviewed publications, national award applications, and educational interventions with providers and seniors in some counties. An outreach strategy is needed to disseminate the learning and the need for senior-friendly food safety and nutrition information statewide and nationally. In the long term, the MFSFS data and lessons learned could be used to develop a comprehensive UCCE nutrition, wellness and food safety curriculum for at-risk seniors and caregivers in California.
M.L. Blackburn is UC Cooperative Extension Nutrition, Family and Consumer Sciences Advisor, Alameda County; C.M. Bruhn is UCCE Food Marketing Specialist and Director, Center for Consumer Research, UC Davis; L. Soederberg Miller is Associate Professor, Human and Community Development, and Director, Adult Development Lab, UC Davis; C. Ganthavorn is UCCE Nutrition, Family and Consumer Sciences Advisor, Riverside County; B. Ober is Professor, Human and Community Development, UC Davis.

The authors thank the following individuals for their assistance with the design of protocol and curricula, data collection, food safety training, and pre-and post-evaluation of the MFSFS study: Margaret Johns, UCCE Nutrition, Family and Consumer Sciences Advisor, Kern County; Rachel A. Surls, UCCE Sustainable Food Systems Advisor, Los Angeles County; Diane Metz, UCCE Nutrition, Family and Consumer Sciences Advisor Emeritus, Yolo County; Anna Martin, UCCE Nutrition, Family and Consumer Sciences Advisor, San Joaquin County; Dorothy Smith, UCCE Nutrition, Family and Consumer Sciences Advisor, Calaveras County; Patti Wooten-Swanson, UCCE Nutrition, Family and Consumer Sciences Advisor, San Diego County; Gloria Barrett, Director and UCCE Community Development/Public Policy Advisor (retired), Sacramento County; Barbara Gillogly, Chair, Gerontology Department, American River College; Maria Giovanni, Assistant Professor, Chico State University; and Charles Brown, UCCE Research Assistant, Alameda County.

\section{References}

Almanza BA, Namkung Y, Ismail JA, Nelson DC. 2007. Clients'safe food-handling knowledge and risk behavior in a Home-Delivered Meal Program. JADA 107(5):816-21. http://dx.doi.org/10.1016/j.jada.2007.02.043.

Barrett G, Swanson PW, Song A. 2005. Evaluation of training program for caregivers to aging adults. J Extension 43(3). www.joe.org/joe/2005june/rb6.shtml.

Blackburn M. 2010. Limited-income seniors report multiple chronic diseases in quality-of-life study. Calif Agr 64(4):195-200.

Blackburn M, Gillogy B, Hauselt P. 2010. Research is needed to assess the unique nutrition and wellness needs of aging Californians. Calif Agr 64(4):167-73. Bohn S, Danielson C, Levin M, et al. 2013. The California Poverty Measure: A New Look at the Social Safety Net. San Francisco, CA: Public Policy Institute of California. www.ppic.org/main/publication.asp?i=1070.

Brookmeyer R, Johnson E, Ziegler-Graham K, Arrighi HM 2007. Forecasting the global burden of Alzheimer's disease. Alzheimers Dement 3:186-91.

[CAPA IHSS] California Association of Public Authorities for In-Home Support Services. www.capaihss.org/ (accessed October 10, 2012).

Cates S, Kosa KM, Karns S, et al. 2009. Food safety knowledge and practices among older adults: Identifying causes and solutions for risky behaviors. J Nutr Elderly 28(2):112-26

[CDC] Centers for Disease Control and Prevention. 2011a. Healthy aging: Helping people to live long and productive lives and enjoy a good quality of life. http://www. cdc.gov/chronicdisease/resources/publications/AAG/ aging.htm.
CDC. $2011 \mathrm{~b}$. Vital signs: incidence and trends of infection with pathogens transmitted commonly through food--foodborne diseases active surveillance network, 10 U.S. sites, 1996-2010. MMWR Morb Mortal Wkly Rep 60:749-55.

CDC. 2011c. Foodborne Diseases Active Surveillance Network (FoodNet): FoodNet Surveillance Report for 2010 (Final Report). Atlanta, GA: U.S. Department of Health and Human Services, CDC. www.cdc.gov/foodnet/ PDFs/2010_annual_report_508c.pdf.

[CSPI] Center for Science in the Public Interest. 2011. All Over the Map: A 10-Year Review of State Outbreak Reporting. Washington, D.C.: The Center for Science in Public Interest. http://cspinet.org/new/pdf/alloverthemap.pdf.

Dutram K, Cook RA, Bagnulo J, Lincoln WL. 2002. Trends in nutritional risks and effect of nutrition education among low-income elders in Maine. J Nutr Elderly 21(4):3-19.

Fey-Yensan N, English C, Ash S, et al. 2001. Food safety risk identified in a population of elderly home-delivered meal participants. JADA 101(9):1055-7.

Hoffman GJ, Lee J, Mendez-Luck CA. 2012. Health behav iors among Baby Boomer informal caregivers. Gerontologist 52(2):219-30.

Kendall P, Hillers V, Medeiros L. 2006. Food safety guidance for older adults. Clin Infect Dis 42:1298-304

Kosa KM, Cates SC, Godwin SL, et al. 2011. Effectiveness of educational interventions to improve food safety practices among older adults. J Nutr Gerontol Geriatr 30(4):369-83.

Kosa KM, Cates SC, Karns S, et al. 2007. Consumer home refrigeration practices: Results of a web-based survey. J Food Protect 70(7):1640-9.
Krisberg K. 2005. Public health workforce not prepared for aging population: Increasing number of seniors on horizon. Nations Health/APHA May:20-1.

Lando A, Chen C. 2012. Trends in ownership and usage of food thermometers in the United States 1998 through 2010. J Food Protect 75(3):556-62.

Lee KE, Yi NY, Park JY. 2009. Food safety knowledge and home food practices of home delivered meal service recipients. J Korean Soc Food Sci Nutr 38(5):618-25.

Mead PS, Slutsker L, Dietz V, et al. 1999. Food-related illness and death in the United States. Emerg Infect Dis 5(5):607-25

Miller LMS. 2010. Cognitive and motivational factors support health literacy and acquisition of new health information in later life. Calif Agr 64(4):189-94.

Miller LMS, Zirnstein M, Chan P. 2013. Knowledge differentially supports memory for nutrition information in later life. J Health Psychol 18(9):1141-52.

Ober BA. 2010. Memory brain and aging: The good, the bad and the promising. Calif Agr 64(4):174-82.

Scharff R. 2012. Economic burden from health losses due to foodborne illness in the United States. J Food Protect 75(1):123-31.

[UC ANR] UC Division of Agriculture and Natural Resources. 2010. The Golden State goes gray: What aging will mean for California. Calif Agr 64(4).

Wallace SP, Pourat N, Enriquez-Haass V, Sripipatana A 2003. Health of Older Californians: County Data Book. UCLA Center for Health Policy Research, Los Angeles, CA. Wang M. 2000. Foodborne Disease Outbreaks in California 1998 by Location of Food Preparation. California Nutrition Council, Los Angeles, CA. 